\title{
COMPONENTES SOCIAIS DA MIGRAÇÃO: EXPERIÊNCIAS DA PROVÍNCIA SUL, ZÂMBIA ${ }^{1}$
}

\author{
Social components of migration: experiences \\ from Southern Province, Zambia \\ Lisa Cliggett*
}

\begin{abstract}
RESUMO
As suposições comuns atribuem causas econômicas e ambientais às decisões de migração. Este trabalho revela a importância das estruturas do poder local - ao nível da comunidade e da família - para entender a migração. São examinados os processos migratórios na Província Sul da Zâmbia por meio do uso de informações coletadas de dois projetos de pesquisa qualitativa. Até recentemente, quando a seca e as doenças bovinas começaram a devastar a área, a Província Sul era conhecida por suas condições ideais para agropecuária. Até os últimos anos de 1980, os agricultores da Província Sul começaram a migrar para áreas da fronteira norte, onde há terra e chuva em abundância. Contextos locais econômicos e ambientais eram os fatores decisórios na migração das populações; o controle sobre os recursos da zona rural e a habilidade de mobilizar as redes de apoio social nos vilarejos também demonstraram influenciar as decisões para deslocar-se. As informações apresentadas nesse trabalho são do Projeto de Pesquisa longitudinal Gwembe Tonga (GTRP) e de um estudo de dois anos sobre emprego e mercados de trabalho na Província Sul, liderados pelo Centro de Estudos sobre Desenvolvimento da University of Bath, Inglaterra.
\end{abstract}

Palavras-chave: migração; agricultura; família; domicílio; economia; África; Zâmbia.

\footnotetext{
ABSTRACT

Common assumptions attribute migration decisions to economic and environmental causes. This paper reveals the importance of local power

" Department of Anthropology. University of Kentucky.

1 Publicado originalmente em: Human Organization, v. 59, n. 1, 2000. Copyright 2000 by the Society for Applied Anthropology. Tradução: Jefferson Olivatto da Silva, UNICENTRO-PR (Guarapuava).
} 
structures - at community and household levels - in understanding migration. It examines migration processes in Zambia's Southern Province using data collected from two qualitative research projects. Until recently, when droughts and cattle diseases began to plague the area, Southern Province was known for its ideal farming conditions. Since the late 1980s, environmental and economic contexts factor into people's migration decisions, control over farming resources and the ability to mobilize social support networks in home villages also influence people's decision to relocate. Data presented in this paper come from the longitudinal Gwembe Tonga Research Project (GTRP) and a two-year study on employment and labor markets in Southern Province, headed by the Development Studies Center, University of Bath, England.

Keywords: migration; agriculture; family; household; economy; Africa; Zambia.

\section{Introdução}

Noções do senso comum sobre migração dizem-nos que aquelas pessoas que mudam para novos lugares têm por objetivo melhorar sua "qualidade de vida". As interpretações desse tipo, tipicamente, privilegiam motivações econômicas: as pessoas se mudam para outros lugares onde elas podem conseguir mais dinheiro ou mais comida e deixam os lugares em que há poucas oportunidades de obter dinheiro ou cultivo. Mas, a qualidade de vida inclui, também, os ambientes sociais nos quais as pessoas se sustentam. $\mathrm{Na}$ maior parte do mundo desenvolvido, as estruturas sociais se conectam às relações hierárquicas e de poder que diretamente moldam as oportunidades econômicas, tanto nos espaços de origem quanto nos pontos de destinos de migração. Na Província Sul da Zâmbia, o crescente ritmo de migração para as fronteiras das áreas de plantio ao norte amplia questões relativas às causas e aos efeitos dessa migração voluntária em larga escala. Este artigo avança na discussão da migração voluntária sugerindo que a organização social e seus conflitos sobre o acesso aos recursos têm um importante papel nas decisões migratórias, como também os fatores econômicos e ecológicos.

Na Zâmbia, como em outros lugares, a falta de terra e o pouco acesso aos implementos agrícolas representam tanto questões econômicas 
quanto sociais. Enfatizando o fator social no molde econômico, desafiamos as suposições sobre os grupos familiares cooperativos e altruístas. Dar atenção ao conflito social nas discussões sobre migração nos permite um melhor entendimento da variedade de relações potenciais entre migrantes e seus familiares de origem. Se conflitos sobre os recursos influenciam as decisões de migração, não podemos cegamente assumir que haja laços harmoniosos ou altruísticos entre as comunidades a que se pertence e também com os parentes distantes.

Esse esclarecimento em nosso entendimento sobre as relações sociais se torna particularmente importante quando projetos de desenvolvimento têm em vista os migrantes e seus familiares nos vilarejos, assumindo que os benefícios dados a um serão automaticamente transferidos ao outro. Por exemplo, se os migrantes urbanos recebem altos salários, a maioria dos teóricos admite que seus parentes das comunidades de origem sejam beneficiados de alguma forma, como por meio do aumento de remessas. Alguns legisladores e agentes de desenvolvimento na Zâmbia acreditam que, ao facilitar a migração de membros familiares para as regiões de fronteiras, em último caso, beneficiarão a família que permaneceu em casa. Mas, se as causas para deixar as comunidades de origem incluem relações contenciosas, que obstruem os interesses econômicos, então os esforços e políticas de desenvolvimento destinados a promover a transmissão de riquezas entre migrantes e seus familiares estão fundamentalmente falhos. Neste trabalho, argumento que a migração nem sempre reflete a tomada de decisão de forma cooperativa em termos intrafamiliares, nem tampouco promove benefício coletivo para as famílias. A migração frequentemente ocorre quando há falhas e conflitos, os quais se opõem às relações agregadas e de parentesco.

\section{Modelo teórico}

Até o início dos anos de 1990, quando a seca e as doenças bovinas começaram a flagelar a área, a maior parte da Província Sul da Zâmbia era conhecida por suas condições ideais de agricultura. Dentro da Província Sul, o Distrito de Monze tornou-se foco de vasta expansão comercial da agricultura, tanto de pequenos "agricultores emergentes" quanto de agricultores 
de subsistência. Os residentes dessa área se beneficiaram de solos e clima favoráveis e de fácil acesso aos centros comerciais ao longo da estrada de ferro. Embora contido dentro das fronteiras da Província Sul, o Vale de Gwembe contrasta bruscamente com o Distrito de Monze e com uma área de platô mais ampla em sua ecologia e de acesso aos centros comerciais. A região do Vale de Gwembe está ao sul e 2.000 pés abaixo do Distrito de Monze e do platô da Província Sul². Entretanto, as condições ambientais e geográficas limitam a habilidade de a população Gwembe se alimentar sozinha consistentemente, para poder participar de uma economia nacional mais ampla e regularmente.

Em ambas as regiões, as pessoas podem melhorar as condições de cultivo com sucesso imigrando para a fronteira com áreas de plantio onde os solos são mais férteis e a chuva é mais abundante. Como Boserup (1965) sugere, quando as populações em uma dada área crescem e a fertilidade do solo declina com o tempo pelo uso repetitivo, as pessoas devem tomar decisões sobre intensificar o cultivo ou se mudarem. Na Província Sul da Zâmbia, as pessoas têm aumentado a escolha pela migração quando o acesso às condições favoráveis de terras cultiváveis se torna mais limitado. Nesse caso, a migração se torna um resultado para essas pessoas de terras sem extensões suficientes e férteis.

As teorias migratórias argumentam que a maximização da riqueza explica a mobilidade geográfica (ANTEL, 1980; DeJONG; GARDNER, 1981; MASSEY, 1990). A maior parte da literatura econômica e sociológica situa a tomada de decisão de migração dentro do modelo dos fatores de push and pull e menciona as redes sociais apenas como facilitadoras do processo migratório (MASSEY, 1993; STARK, 1991; TODARO, 1994). De acordo com esses argumentos, migrantes potenciais vivendo em condições marginais buscam melhores oportunidades econômicas para aprimorar seu próprio - e de sua família - bem-estar econômico. Isto é, pobres condições nos espaços de origem "empurram" migrantes para fora de áreas com atraso econômico e economias vibrantes nas cidades e regiões mais desenvolvidas

2 Distrito de Sinazongwe no extremo nordeste do vale, Distrito Central de Gwembe e Distrito de Siavonga, que inclui o extremo sudoeste do vale. Antes de 1992, o vale como um todo estava dentro do Distrito de Gwembe. O vale é a moradia de uma população culturalmente distinta, conhecida como Vale de Gwembe Tonga. Há diferenças regionais sutis na língua e práticas culturais dentro do vale de um extremo ao outro, mas, no restante da Zâmbia, a população do vale é considerada como sendo um único grupo étnico. 
"puxam" aqueles migrantes de seus lares. As redes sociais que se encontram entre o lar e os pontos destinatários - o caminho das pedras criado pelos migrantes anteriores - facilitam o novo passo migrante para novas terras (MASSEY et al., 1987; SINGER; MASSEY, 1998). A maior parte dessa literatura vê os migrantes agindo como membros altruístas de suas famílias, agregados e comunidades, não apenas como agindo por "interesses próprios de ganância"; dessa forma, explicando as redes sociais de ajuda de outros migrantes e as remessas que os migrantes enviam para casa (BERTRAM, 1999; DaVANZO, 1980; MASSEY et al., s/d.).

Muitos estudos migratórios acham que os migrantes realmente enviam remessas para suas comunidades de origem (LUCAS; STARK, 1985; MASSEY, 1993; STARK, 1991; TODARO, 1994). Entretanto, o tipo, a quantidade e os usos dessas remessas permanecem incertos, deixando em aberto o benefício real das remessas para as comunidades enviadas (HAYES, 1991; JONES, 1995).

Em pelo menos um caso na Zâmbia, migrantes enviaram "remessas" primeiramente para reservar seu direito de retornar para as comunidades de origem; os recursos enviados de volta para os parentes eram mais gestos simbólicos do que recursos materiais para melhorar a qualidade de vida para o receptor (CLIGGETT, 1997). Outro estudo na Zâmbia encontrou que os "migrantes que retornaram" preferem não retornar aos vilarejos de origem, mas, ao contrário, se estabelecer em áreas vizinhas para evitar o contato fácil e frequente com parentes dos vilarejos de origem (ASBAUGH, 1996). Essas descobertas sugerem que migrantes nem sempre mantêm ligações de benefício mútuo com seus parentes de origem. Em alguns casos, como esse trabalho demonstra, a migração oferece uma fuga dos parentes.

Por toda a África, as relações sociais estruturam o acesso aos recursos materiais (GUYER, 1981). Na Zâmbia, as estruturas sociais misturam-se com fatores econômicos para criar incentivos complexos para a migração. Aqui, usei as informações coletadas em dois diferentes estudos para demonstrar como ligações sociais e relações de poder local influenciam quem tem acesso a determinados recursos, inclusive terra e implementos agrícolas, $\mathrm{e}$, consequentemente, por que alguns membros dos vilarejos migram para longe de redes estabelecidas de apoio socioeconômico. Por essa visão de migração, as decisões para se mudar refletem o rompimento com as normas de assistência familiar, altruísmo e cooperação familiar. 
Dentro da economia neoclássica, suposições sobre tomada de decisão familiar sugerem que grupos domésticos cooperam para o benefício do grupo e os "ditadores benevolentes" que dirigem as famílias tomam decisões a favor de sua família (BECKER, 1981). A maioria dos estudos sociológicos de migração também se subscreve a essa visão doméstica.

A antropologia oferece visões mais amplas de famílias e seus membros, inclusive da tensão entre indivíduos e seu grupo doméstico (COLSON, 1995a, 1995b; NETTING, 1993; NETTING et al., 1984; WILK, 1989). Disputas entre novas e antigas gerações podem influenciar na prática de herança e de cuidados mútuos (GREENHALGH, 1988; STUCKI, 1995; UDVARDY; CATTELL, 1992) e, nos estágios do ciclo da vida, influenciam como e quando os migrantes participam nas atividades domésticas que eles deixaram para trás (TOWNSEND, 1997). O caso da Zâmbia sustenta essas visões informadas antropologicamente sobre a economia doméstica. Indivíduos em grupos domésticos participam em lutas complexas para encontrar suas próprias necessidades, geralmente resultando em fissuras nas alianças familiares. As dinâmicas sociais entre os pais e o filho causam ao filho a perda do acesso ao gado e ao arado de seu pai, não restando alternativa para cultivar seu próprio campo. A divisão da terra decorrida da morte de um ancião comumente deixa pelo menos um parente sem terras. Em tais circunstâncias, a migração pode se tornar uma solução preferida à insegurança material causada pelo conflito social.

\section{Contexto cultural: sistemas matrilineares de transmissão de propriedade}

Os sistemas culturalmente construídos de posse de terra e de herança na Província Sul revelam a complexidade da organização social local. A maioria das populações da Província Sul pratica a descendência matrilinear, que delineia identidade e propriedade por parentes femininos. Um jovem rapaz obtém sua identidade social primária do clã de sua mãe e espera herdar a propriedade do irmão de sua mãe, não de seu pai. Da mesma forma, uma jovem cuida de sua mãe e dos parentes de sua mãe para herdar a 
propriedade. Em princípio, essa propriedade pertence ao clã matrilinear, mas durante a vida as pessoas associam propriedades particulares a indivíduos particulares. Um indivíduo tem o direito de dar ou alugar sua propriedade para outra pessoa dentro da linha matrilinear.

O gado e a terra são os tipos de propriedades mais importantes que seguem o padrão de transmissão. Diante da morte de um homem rico, irmãos, irmãs e filhos de irmãs negociam sobre quem irá conseguir o gado mais valioso e os campos férteis próximos às fontes de água. Essas negociações, geralmente, tornam-se discussões calorosas, que podem levar meses para se resolver. O sistema matrilinear estabelece um molde sobre o qual as pessoas agem, não havendo regras definidas que identifiquem herdeiros primários. Um terceiro filho tem tanto direito à propriedade de seu tio quanto o primeiro filho. Um jovem rapaz em seus 20 anos pode receber uma vaca da irmã de sua mãe, enquanto a irmã mais velha da mulher falecida nada recebe. Obviamente, este modelo matrilinear flexível permite que haja muitos momentos de contestação.

Entre os Tonga, o grupo étnico que habita os campos da presente pesquisa deste artigo, em um sistema de dote da noiva (lobola), ecoando em tendências mais patrilineares, acrescenta-se um desafio adicional às fortes estruturas matrilineares de identidade e transmissão de propriedade ${ }^{3}$. A maior parte do gado dado pela família do noivo à família da noiva vai para o pai da noiva, não para os parentes matrilineares. Esse sistema resulta na grande expectativa dos pais sobre os casamentos de suas filhas, pois os homens podem acumular grandes riquezas por meio dessas trocas. Como um informante relatou: 'Eu quero que minha filha case logo para 'comer' o gado dela!"4. Esses gados podem então se tornar riqueza em seu clã, ao qual seus irmãos, irmãs e filhos das irmãs terão acesso.

O direito do pai ao trabalho de seus filhos também tempera os sistemas matrilineares de propriedade. Filhos e filhas, assim como as esposas, fornecem um importante trabalho agrícola nos campos dos homens.

3 O Platô e o Vale Tonga constituem grupos étnicos separados e únicos, apesar de partilharem o mesmo nome. Em um nível muito amplo, eles partilham padrões sociais, como uma organização social matrilinear ligada por identidades de clã. Para mais detalhes específicos sobre os grupos étnicos da Província Sul, e em particular os Tongas, ver Colson (1980 e 1996), Colson e Gluckman (1951) e Mitchell (1956).

4 Quando os falantes Tonga e outros zambianos dizem que querem "comer" alguma coisa, eles implicam que o objeto de "consumo" é um objeto de luxo ou valioso. Os Tongas valorizam o gado tanto como uma riqueza econômica como status social. No caso dos meus informantes, acumular gado ("comer" gado) dará a ele segurança material, assim como respeito dentro da comunidade. 
Enquanto as crianças e as esposas, normalmente, comem da comida desses campos, não se beneficiarão necessariamente de qualquer lucro obtido de uma colheita extra ou do dinheiro das vendas. O lucro pertence ao pai, podendo fazer o que quiser com seus ganhos.

Claramente, esses sistemas de oposição da extração do trabalho pelos pais e maridos, transmitido de propriedade pelas mães e seus parentes, podem resultar em uma profunda tensão e conflito incorporados entre membros da família. Essas disputas podem facilmente se transformar em gatilhos para a mudança domiciliar para um lugar onde as estruturas sociais permitam melhores oportunidades para crescimento das condições materiais de sobrevivência.

Qualquer discussão sobre migração que ignore os ambientes sociais locais e o contexto cultural dos sistemas de economia como parte do processo de tomada de decisão não tem a profundidade e a sutileza necessárias para tecer conclusões úteis. Pelo entendimento dos mundos sociais de que os migrantes emergem, estamos mais aptos a entender e predizer como eles se comportarão em seus novos ambientes.

\section{Campos de pesquisa e metodologia}

Foquei-me, neste artigo, em padrões entre zonas rurais de migração usando informações coletadas de dois projetos de pesquisas na Província Sul, da Zâmbia. A primeira é um estudo longitudinal de quarenta anos das populações do Vale de Gwembe; a segunda é parte de um estudo de dois anos sobre emprego e mercados de trabalho no Distrito de Monze.

O Projeto de Pesquisa Gwembe Tonga (Gwembe Tonga Research Project - GTRP), iniciado em 1956, é um estudo antropológico e demográfico enfocado nos efeitos socioculturais de mudança domiciliar forçada das comunidades do Vale do Tonga, causada pelo represamento do Rio Zambezi e subsequente a criação do Lago Kariba. O Vale do Gwembe carrega a reputação por toda a Zâmbia de ser uma região de seca, isolada e empobrecida. As anuais estações de fome, combinadas com secas cíclicas, geralmente tornam a subsistência frágil. As poucas rodovias de acesso 
existentes estão em péssimas condições, tornando, tipicamente, o acesso aos ganhos de mercado e o não cultivo algo difícil.

Por mais de quarenta anos, os dois especialistas seniores do projeto, Elizabeth Colson e Thayer Scudder, coletaram uma variedade de informações quantitativas e qualitativas; inclusive, censos regulares das vilas, informação socioeconômica das famílias e da região como um todo; mapas agrícolas e informações etnográficas coletadas com os métodos antropológicos tradicionais. Os dados Colson-Scudder incluem informação sobre a migração laboral tanto quanto assentamento de terra. Em 1994, juntei-me ao Projeto de Pesquisa Gwembe Tonga e iniciei um estudo de sistemas de apoio de famílias extensas para os anciãos em duas das quatro amostras de vilarejos do GTRP. Entre março de 1994 e setembro de 1995, orientei uma pesquisa antropológica nas comunidades Gwembe e em pequenas cidades e outras áreas agrícolas, onde os moradores dos vilarejos dos Gwembe assentaram-se. Parte do meu foco era entender as ligações entre crianças migrantes e seus parentes nos vilarejos de origem. Nesse artigo, usei os dados de minha própria pesquisa e os dados de quarenta anos do estudo GTRP.

Minha participação no estudo de emprego e trabalho de Monze da University of Bath (Reino Unido) começou em agosto de 1996, quando realizava dois meses de pesquisa qualitativa nas quatro comunidades pesquisadas do Distrito de Monze e nos destinos de fronteira dos migrantes ao norte e a leste de Lusaca, capital da Zâmbia. Retornei ao estudo das comunidades e destinos migrantes por mais um mês de pesquisa em agosto de 1997. Meus métodos incluíam entrevistas com líderes, anciãos e outros membros da comunidade, com um foco nos padrões de migração dos vilarejos às áreas de fronteiras agrícolas. Também encontrei migrantes em tais áreas de destino para coletar histórias de migração e discutir o processo de tomada de decisão.

O Distrito de Monze contrasta-se com o Vale de Gwembe por seu acesso aos centros comerciais locais, transporte e, historicamente, pelas boas condições de cultivo. O distrito é cortado pela estrada de ferro, com sua principal cidade, Monze, em seu centro. Agricultores podem trocar ou vender seus produtos para os mercados locais ou dentro de seu próprio vilarejo e para os intermediários que vêm da cidade para comprar a granel, ou eles mesmos podem levar o excedente para a cidade e vendê-lo. Mas, desde o começo da década de 1990, a maior parte da Zâmbia sofreu com 
sérias secas, particularmente a Província Sul, que tem sido a região mais árida do que as outras que estão ao norte. O Distrito de Monze, que era chamado como o maior produtor de grãos da Zâmbia, sofreu suas secas mais sérias desde o começo dos anos de 1920 e 1994 (SAVORY, 1996).

Os dois estudos se diferem não apenas por suas características físicas, mas também pelas metodologias que empreguei. Os moldes temporais de cada estudo requereram diferentes estratégias de coleta de dados. Durante os anos de 1994 e 1995, vivi em um vilarejo central Gwembe, no qual conduzi uma tradicional pesquisa antropológica de observação participante. Nesse período, minha pesquisa teve como foco 45 adultos com idade de 50 anos ou mais e todos os seus filhos, onde quer que estivessem. Complementei meu intenso conhecimento dessa mesma comunidade com informações colhidas por visitas periódicas a outro vilarejo da amostra do GTRP no Gwembe Norte. Com a ajuda de meu assistente, conduzi extensas entrevistas abertas e colhi informações padronizadas sobre as atividades familiares produtivas, padrões de residência e características demográficas. Em ambos os vilarejos, beneficiei-me com a confiança que foi desenvolvida ao longo do tempo e a familiaridade com que as comunidades tinham com a pauta de pesquisa do GTRP.

O estudo Monze demandou mais coleta de dados sistematizados e durante as primeiras semanas de estudo desenvolvi dois questionários que formaram as primeiras fontes de dados. Usando um questionário, entrevistei 15 chefes locais (ou anciãos dos vilarejos) para juntar informações acerca de 73 migrantes das quatro áreas da amostra Monze. Esses 73 migrantes constituíram o total da lista de todos os migrantes recordados pelos registros dos chefes ou anciãos desde que os vilarejos foram formados. As entrevistas com os chefes locais ou anciãos se basearam na memória, a partir da recordação de datas e francas conversas que, algumas vezes, se tratavam de dados particulares da vida das pessoas. Por essas razões, não tive todos os aspectos da vida dos migrantes, mas apenas do que os líderes podiam se lembrar e desejavam discutir com uma estranha.

O segundo questionário focou nas experiências individuais da migração. Meus assistentes e eu viajamos para o nordeste de Lusaca para rastrear e entrevistar migrantes de Monze. Usando o questionário, conduzimos entrevistas intensas com uma amostra de 25 migrantes de seis diferentes distritos agrícolas do norte e leste de Lusaca. Fazer o rastreamento 
de indivíduos específicos em um vasto território demanda muito tempo e dinheiro, por isso apenas três membros dessa amostra foram tomados da lista de 73 migrantes originários de Monze. Encontramos os outros 22 migrantes na fronteira com a ajuda de administradores das fazendas locais. O questionário se dirigia a questões de disponibilidade de recursos para $\mathrm{o}$ migrante, inclusive redes sociais, antes de sua partida do vilarejo de origem e após terem chegado à nova área. Também conduzimos conversas em grupo com agricultores em reuniões e em depósitos de grãos, onde, então, encontramos um grande número de migrantes da Província Sul.

Juntar informação da migração de mulheres provou ser o problema mais difícil que encontrei durante a coleta de dados no projeto de Monze. Os chefes das vilas e os anciãos (todos homens) geraram listas de migrantes de seus vilarejos por meio de uma variedade de situações baseada no contexto (na seção do processo de migração discuti os detalhes para identificar os migrantes). Apenas porque uma pessoa se mudou do vilarejo não significa que os chefes ou anciãos identificam-na como um(a) migrante. Quando as mulheres deixam o vilarejo por conta própria (sem a companhia de um marido, irmão ou pai), os chefes locais, geralmente, não a identificam como migrante. Um ancião disse sobre a ausência de uma mulher: "Ah, ela apenas foi visitar sua irmã em uma fazenda do norte", de fato, mas esta mulher estava vivendo na fronteira por pelo menos um ano. As mulheres não se mudam tão livremente quanto os homens, nem se mudam de forma independente. Na maioria dos casos, as mulheres se mudam com um marido ou pai. As hipóteses locais sobre as decisões do homem da família davam detalhes sobre essas mulheres "dependentes" e, também, homens "dependentes", por conta das discussões não formais sobre os migrantes. Consequentemente, meus dados sobre as mulheres são mais anedóticos e advêm em sua grande parte das comunidades Gwembe, onde fiquei a maior parte do tempo e onde tive mais acesso a conversas casuais e dados coletados informalmente.

Ser capaz de comentar sobre a migração das mulheres, dadas as dificuldades que encontrei no estudo de Monze, atesta o valor da incorporação de resultados de diferentes projetos para explorar um tema comum. Esses dois estudos, com sua variação de características ecológicas e econômicas e métodos variados complementários, forneceram uma visão ampla do processo de migração da região sul da Zâmbia. 


\section{Padrões de migração Gwembe e Monze}

A migração não é um fenômeno novo na Zâmbia. As populações móveis moldaram a história da Zâmbia antes e durante a era colonial. Este artigo se foca nos padrões de migração contemporânea. Para discussões históricas, ver Chipungu (1992), Colson (1958), Moore \& Vaughan (1994), Seleti (1992) e Vail (1983).

Os padrões de migração domésticos da Zâmbia por todo o século passado seguiram, predominantemente, o caminho rural-urbano (OHADIKE, 1981). Colson e Scudder confirmam que as populações da Província Sul, historicamente, seguiram o padrão nacional de migração por trabalho das áreas rurais para centros comerciais (COLSON, 1958, 1960, 1971; COLSON; SCUDDER 1975, 1981). Mas, nas últimas duas décadas, os agricultores da Província Sul intensificaram a escolha pelos destinos rurais para migração do que para pequenas ou grandes cidades (MAFF, 1995; SCUDDER; HABARAD, 1991).

O censo de 1994 do GTRP do estudo dos vilarejos Gwembe indica que $30 \%$ de toda a população acima da idade de 20 anos vivem fora da região do vale. Destes, $34 \%$ residem na capital da Zâmbia (Lusaca), $20 \%$ se estabeleceram na região fronteira de cultivo a noroeste do Vale de Gwembe (Chikanda) e 10\% se mudaram das regiões de cultivo a noroeste para a capital. $\mathrm{O}$ restante se estabeleceu em áreas ao longo da estrada de ferro, que incluem comunidades agrícolas e pequenas cidades (veja Tabela 1 e Figura 1).

Os dois vilarejos da amostra do GTRP no extremo norte do vale se beneficiam da oportunidade de ganhar dinheiro perto de casa pelo fato de os centros de agronegócio se situarem dentro de 40 milhas de suas comunidades. Aproximadamente 5 homens desses vilarejos encontraram trabalho nas fazendas no início dos anos de 1990. Nos últimos dois anos, os parentes desses primeiros "exploradores", inclusive mãe e irmãs, encontraram emprego na mesma companhia e as famílias extensas vivem juntas em comunidades ao redor da fazenda (BOND et al., 1997).

Na mesma época, assim como as comunidades do Vale de Gwembe, as populações Monze migraram para as cidades e, de forma gradativa, para as áreas agrícolas ao norte. Dos 73 migrantes da área Monze de quem tive informações, aproximadamente $32 \%$ se mudaram das áreas rurais a cerca 
Figure 1. Migration Patterns from the Gwembe Valley and Monze District

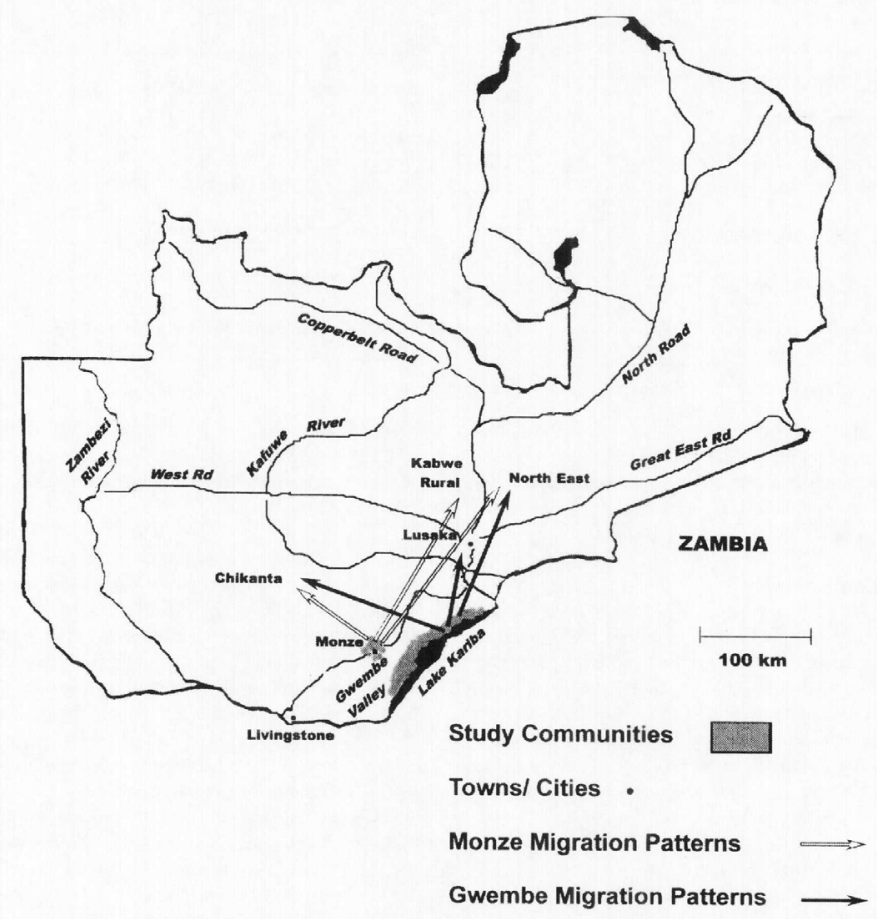

FIGURA 1 - PADRÕES MIGRATÓRIOS DO VALE DE GWEMBE E DISTRITO DE MONZE

de $70 \mathrm{~km}$ ao norte de Lusaca (zona rural de Kabwe). Cerca de 1.500 famílias Tonga da província Sul chamam uma parte da zona rural de Kabwe, informalmente conhecida como "Nova Monze", de casa. Outros 32\% dos migrantes se mudaram para uma área ainda mais distante a nordeste de Lusaca (ver Tabela 2 e Figura 1). As populações Monze também se mudaram para áreas mais próximas de uma nova região em seu próprio distrito ou em distritos vizinhos na Província Sul, assegurando campos maiores e a escritura de suas terras. 
TABELA 1 - DESTINOS MIGRATÓRIOS PARAAAMOSTRA GTRP, ADULTOS ACIMA DE $20^{*}$ ANOS

\begin{tabular}{lcc}
\hline & N & \% \\
\hline Lusaca (capital zambiana) & 209 & 33 \\
Chikanda (fronteira da Província do Sul) & 121 & 19 \\
Norte e/ou Leste de Lusaca & 85 & 13 \\
Linha ferroviária e áreas de cultivo & 220 & 34 \\
Outro & 5 & 1 \\
Total de migrantes GTRP acima de 20 anos & 640 & 100 \\
\hline
\end{tabular}

FONTE: Censo GTRP 1994.

* Total de pop. GTRP acima de 20 anos é de 2081

TABELA 2 - DESTINOS MIGRATÓRIOS PARA A AMOSTRA MONZE

\begin{tabular}{lcc}
\hline & N & $\mathbf{\%}$ \\
\hline Área rural de Kabwe e vizinhanças & 23 & 32 \\
Norte e/ou Leste de Lusaca & 231 & 32 \\
Chikanda (fronteira da Província Sul) & 8 & 11 \\
Distrito de Monze (fora do vilarejo de origem) & 11 & 15 \\
Linha ferroviária e áreas de cultivo & 8 & 11 \\
Total de migrantes na amostra Monze & 73 & 101 \\
\hline
\end{tabular}

FONTE: Chefes e anciãos do vilarejo.

* Total não é igual a 100\% devido ao fator de arredondamento.

\section{O processo migratório}

Os agricultores migrantes, tanto do Vale de Gwembe como da área Monze, geralmente deixavam seus próprios vilarejos para se juntar aos parentes com prósperas fazendas nos assentamentos da fronteira. Nessas áreas, resolutos agricultores podem reivindicar entre 50 e 300 hectares da nova terra das abundantes florestas. Jovens rapazes, que não controlam o trabalho nem têm recursos para limpar seus próprios campos, logo quando chegam se agregam a parentes mais velhos com grandes áreas e se tornam uma força de trabalho adicional e bem-vinda. Dentro de 3 a 5 anos, a maioria 
dos novos migrantes possui seus próprios recursos agrícolas, limpa seus próprios campos e fixa sua moradia e sua fazenda independentemente.

Mesmo quando migrantes, vivendo na nova área por vários anos, estabelecendo-se na sua própria fazenda, chefes e líderes da comunidade não os reconhecem de forma automática como residentes oficiais da nova área. Para receber o reconhecimento oficial de novos residentes, migrantes devem portar uma carta de apresentação do antigo chefe de sua comunidade requisitando que o chefe da nova área os inclua na lista do registro do vilarejo. Esse tipo de documento assinala o fim de sua antiga residência e o reconhecimento oficial com a outra localidade.

Enquanto essas novas áreas de fronteira geralmente oferecem melhores oportunidades agrícolas, migrantes e seus familiares dos vilarejos reconhecem uma variedade de vantagens para evitar um rompimento oficial com a comunidade de origem. Mantendo, oficialmente, residência nos vilarejos de origem, isto é, sem pedir para ser listado no registro do chefe do vilarejo da nova localidade, o migrante pode facilmente retornar se as condições da nova área se tornam indesejáveis. Ademais, a residência oficial no vilarejo de origem permite ao indivíduo receber auxílio de alimento, um importante incentivo nas comunidades que, regularmente, se pautam em assistência de alimento durante a comum intensificação das secas.

Durante 1994 e 1995, vi, em muitas ocasiões, quando os nomes dos migrantes de longa data eram incluídos no programa de auxílio rural de alimento em seus antigos vilarejos, pois suas residências oficiais ainda eram os vilarejos. Se um membro da família vive distante de seu vilarejo, mas se mantém listado no registro deste vilarejo, ele ou sua família pode submeter os seus nomes para receber auxílio ou outro tipo de assistência. Nitidamente, manter o status oficial no vilarejo de origem tem benefício tanto para o migrante quanto para sua família. De fato, a migração é um processo lento, que inclui a residência informal a longo prazo no destino antes de buscar o status oficial dos líderes da comunidade.

Devido ao comum longo processo antes de estabelecer residência permanente, os anciãos dos vilarejos preferiam relatar sobre todos os agregados que deixaram o vilarejo a dizer sobre os indivíduos que saíram do local para explorar possibilidades em novas áreas. Mesmo em conversas informais, os anciãos, geralmente, não reconheciam uma migração até que tenha sido feito o pedido oficial, tanto pelo migrante quanto pelo chefe do vilarejo. Esse viés resultou em enfatizar migrações que estavam nos 
estágios finais de se tornarem oficiais, em oposição a estágios de migração quando os indivíduos deixam os vilarejos para buscar informações acerca de oportunidades em novas terras. Outros moradores dos vilarejos, entretanto, compartilharam histórias comigo de homens e mulheres que vieram e foram por períodos de tempo, como parte do processo migratório.

\section{A migração feminina}

As estruturas de poder de gênero na Zâmbia encobrem muitas ações femininas como esposas, filhas e mães no contexto de migração, pelo rompimento físico com definições sociais da família. Na sociedade Tonga (tanto no platô como no vale), os homens valorizam as mulheres, particularmente as filhas, que irão trazer uma bolada de lobola (o preço do dote da noiva pago aos pais), e as esposas, que gerarão filhas. Por conseguinte, é típico dos homens influenciar e controlar abertamente os movimentos da mulher a fim de proteger seus direitos sobre ela.

Quando a mulher, tanto das áreas do Vale do Gwembe quanto das do Monze, deixa seus vilarejos de origem, ela na maioria das vezes vai se juntar a um marido, tanto na cidade quanto na área de fronteira. Durante entrevista com as mulheres, elas enfatizaram a dependência de seus maridos ou parentes no processo migratório. Afirmações como "eu apenas segui meu marido para cá" ou "eu vim para cá porque estou casada e não posso simplesmente me divorciar" revelam algumas das atitudes profundamente incorporadas sobre a dependência das mulheres em relação aos homens. Se uma mulher não casada se muda, ela geralmente vai para onde tem parentes, ou pelo menos um amigo próximo. No ambiente urbano, esses contatos auxiliarão na busca por moradia e emprego. Se uma mulher solteira muda-se para alguma outra região rural, ela na maioria das vezes irá se juntar a um parente matrilinear, talvez um irmão ou o irmão de sua mãe.

Em dois casos separados, os pais nas comunidades Gwembe, cada um enviou sua filha para parentes matrilineares em áreas fronteiriças devido à doença da filha. Uma mulher sofria de extremas dores corporais relacionadas ao ciclo menstrual. Ela também era estéril e sua família acreditava que se as dores corporais fossem curadas ela poderia finalmente ter filhos. Em minha 
última visita, ela continuava vivendo com seus parentes na fronteira, mas sua doença não tinha melhorado, nem havia concebido filho algum. A outra mulher sofria de uma doença crônica que alguns dos parentes no vilarejo me disseram ser HIV. Seus irmãos e pais buscaram tanto tratamentos médicos ocidentais como tradicionais em casa, mas tais tratamentos eram caros. Quando, finalmente, enviaram-na para morar com o irmão da mãe na fronteira, eles esperavam que pelo menos os custos dos tratamentos fossem divididos entre uma maior porção de parentes. Ela permaneceu no platô com seu tio por quase 10 meses, se beneficiando de três refeições diárias e tratamentos tradicionais à base de ervas e cura espiritual. Apesar da atenção recebida pela acolhida na casa de seu tio, ela me disse repetidamente que queria voltar para seu vilarejo para estar próxima às suas irmãs. Seu irmão mais velho negou seu honrado desejo, como me confidenciou: "se ela vier para casa serei eu que devo pagar por ela (comida e outras necessidades)." Mas, já quando era óbvio que não viveria por muito mais tempo, o tio a enviou para o vilarejo de origem, onde morreu após três semanas de sua chegada.

A maioria das histórias de migração das mulheres reflete as dinâmicas de poder de gênero similares. Ao mesmo tempo, as histórias de migração por causa de doenças também sugerem que a tensão social sobre como os recursos serão consumidos podem influenciar as decisões familiares sobre onde e com quem filhas e irmãs irão viver. Assim como o gênero, a geração e o ciclo da vida geralmente caem dentro de altas restrições sociais estruturadas. Da mesma forma, jovens rapazes, que algumas vezes caem dentro de relações de dependência similar às situações das mulheres, têm uma maior amplitude de ação em que podem escolher. Os homens não "pertencem" aos familiares da forma como as mulheres pertencem e, assim, suas histórias migratórias demonstram mais independência e fácil movimento entre os vilarejos de origem e as áreas externas.

\section{Por que eles vão: o componente social das decisões migratórias}

O desejo por oportunidades de melhoras econômicas é geralmente assumido ser a razão principal para a maioria das decisões migratórias na 
Zâmbia (CSO, 1995; MAFF, 1995). Interpretações alternativas sobre a oportunidade econômica, entretanto, incluem contextos sociais mais amplos para a tomada de decisão (NETTING et al., 1984; WILK, 1989). Em alguns casos, a oportunidade implica o nível salarial, mas em outros isso pode significar a fuga de influências sociais que limitam a vida. Os dados que surgiram com os estudos Gwembe e Tonga sugerem que o acesso aos recursos produtivos moldou as decisões de migração das pessoas. Nesta sociedade, como em muitas sociedades não ocidentais, as estruturas sociais locais tipicamente determinaram o acesso pelo recurso. Assim, por meio dessa visão, o contexto social da oportunidade econômica profundamente influenciou o que pode ser simplesmente chamado de "decisão econômica".

No estudo Monze, nas comunidades e nas áreas de fronteiras além da região de Lusaca a falta de suficiente terra fértil foi uma importante razão para muitas partidas dos vilarejos de origem. Líderes matrilineares locais, anciãos dos vilarejos e indivíduos negociam quem terá, quanto e qual terra. As decisões migratórias baseadas nesse sentido de oportunidade econômica refletem o ambiente social complexo do vilarejo. Indivíduos, relações de parentesco e comunidades se juntam em negociações pelos recursos, empunhando o poder que têm na forma de capital social e material.

A seca, os problemas ambientais e as estruturas econômicas nacionais e locais certamente acentuam os desafios locais para que haja um cultivo eficiente e próspero. Mas, eles não são as únicas forças que empurram as pessoas para fora de seus vilarejos. Colson e Scudder (1975) forneceram informação sobre a residência e a migração das comunidades de Gwembe Norte, no ano de 1972, que é similar aos dados do GTRP obtidos pelo censo de 1994. Em 1972, por volta da metade da população adulta vivia em seus vilarejos de origem, enquanto cerca de $15 \%$ dos homens estava vivendo nas cidades. De acordo com os dados do censo, em 1994 aproximadamente 16\% dos adultos viviam em grandes ou pequenas cidades, enquanto quase metade da população permanecia nos vilarejos. Colson e Scudder descreveram o início dos anos de 1970 como "bons anos", querendo dizer que a agricultura estava dando bons resultados e as oportunidades econômicas eram muitas. Dado que o início dos anos de 1990 foi um período de seca e dificuldade econômica e as oportunidades de trabalho estavam diminuindo nas cidades, os números similares sugerem que a migração não é simplesmente causada por subsistência ou problemas econômicos em casa. Claramente, outros 
fatores contribuíram para que as pessoas decidissem permanecer ou sair de casa, mesmo em tempos de dificuldades.

Muitos dos jovens das comunidades Gwembe foram relutantes em falar comigo sobre os detalhes de sua partida. Eles, geralmente, dizem que deixaram o vilarejo porque "não havia nada em casa, nem comida nem trabalho". Porém, eu queria saber a razão para uma pessoa sair de casa e outra ficar. Pela observação e discussão com amigos próximos, encontrei jovens rapazes que em muitos casos romperam com a casa do pai por discussões. Os conflitos sobre o uso de equipamentos agrícolas e o controle do pai pelo trabalho do filho geralmente culminavam até a ruptura na aliança pai-filho (ver também COLSON, 1998). Em alguns casos, o jovem rapaz se casa e deseja autonomia para produzir sua subsistência e ganhar dinheiro com a colheita de grãos para si e para sua esposa. Ou, se ele trabalha para seu pai, ele deseja uma compensação adequada pelo seu trabalho. A falta de equipamento agrícola força os jovens rapazes a depender de seus pais, que desejam acumular os ativos valorizados pelo tempo. Scudder e Habarad (1991) sugerem que, com a diminuição da produtividade dos vilarejos Gwembe, os pais não são capazes de recompensar os filhos adultos por seu trabalho.

Enquanto as secas e a falta de alimento podem disparar a decisão da migração para uma pessoa específica em um momento particular, os jovens rapazes preferem deixar o vilarejo aparentemente em qualquer momento, simplesmente para se distanciar de algumas das tensões associadas aos relacionamentos de parentesco próximos. As tensões sociais entre pais e seus filhos podem fazer com que as gerações mais novas anseiem por estabelecer lares independentes. Nessas situações, os jovens rapazes podem ir para as cidades onde possam ganhar o suficiente para comprar seu arado e capinadeiras e também pagar o dote da noiva para obter suas esposas. Ou eles podem se mudar para as áreas de cultivo na fronteira e se agregar a parentes que os assistirão no estabelecimento de suas próprias fazendas.

As tensões sociais dentro da comunidade ampla da família extensa e co-habitantes dos vilarejos podem também encorajar um afastamento de casa pelos fazendeiros mais velhos. Scudder e Habarad (1991) sugerem que muitos residentes de Chikanta, a fronteira noroeste de destino do Gwembe, deixam seus vilarejos por conta da inveja e medo de feitiçaria; nesses casos, a migração é geralmente a escolha preferida para resolver conflitos familiares. Foram em sua maior parte os prósperos e ricos fazendeiros das amostras 
dos vilarejos do GTRP e, consequentemente, os mais suscetíveis a inveja e acusações de atos malignos, os primeiros a se estabelecer em Chikanta. Uma vez estabelecidos, eles convidaram outros parentes, em sua maioria os filhos das irmãs (em uma boa forma matrilinear) de casa para ir auxiliar na limpeza dos campos em troca de terras. Minhas conversas com alguns dos jovens rapazes sobre os pais e os tios que são tidos como feiticeiros apoiam o argumento de Scudder e Habarad.

Durante as entrevistas, tanto relacionadas às comunidades enviadas a Monze quanto aos pontos de destino a nordeste de Lusaca, as pessoas tipicamente falavam sobre problemas de acesso a recursos como a causa primeira para se mudar. Porém, entender o ambiente social que molda o controle sobre os recursos ajuda a revelar as complexas estruturas e tensões de poder, os quais também figuram naquelas decisões migratórias. Quando sondei mais profundamente as motivações pessoais pela migração, eles, eventualmente, explicaram que os conflitos por causa do acesso aos recursos causavam a escolha pela saída dos vilarejos de origem (ver Tabela 3). Dos 68 indivíduos de quem obtive informação sobre as razões de suas partidas, 51 (75\%) deles se mudaram por causa dos problemas ligados ao aproveitamento de recursos suficientes para o plantio. A maioria desses casos (42 de 51) eram problemas associados à distribuição de terras nos próprios vilarejos, um problema estrutural herdado das relações sociais. Um trabalhador urbano retornou ao vilarejo dos pais após sua aposentadoria, porém, quando as discussões surgiram sobre o uso que fez das terras dos parentes, ele decidiu mudar-se ao norte de Lusaca para começar sua própria fazenda. Outro homem me disse acerca da divisão da terra de seu pai quando este faleceu. Este jovem rapaz foi deixado sem nada e escolheu seguir um parente matrilinear para o nordeste de Lusaca. O problema mais comum, de acordo com muitas pessoas na área de Monze, era o grande tamanho da família. As famílias têm muitas crianças e não há simplesmente terra suficiente para distribuir entre todos eles, ao menos alguns filhos em uma extensa família encontrarão novas terras se quiserem ter uma boa fazenda.

Os limites da terra disponível também são considerados por aqueles com desejos empresariais. Três migrantes da região de Monze eram agricultores agressivos que desejavam mais terra para produzir milho em escala comercial. Algumas pessoas também mencionaram a necessidade de ter mais terra para o pastejo quando tinham esperança de criar gado em larga escala. 
Enquanto a seca causou problemas para todos os fazendeiros nos últimos cinco anos, somente oito de 68 pessoas (12\%) citaram a falta de chuva como o fator de motivação pela imigração. Como um ancião do vilarejo relatou-me: "Aqueles que estão afastando a chuva (migrando para o norte) desejarão retornar quando virem que nós estamos bem”, sugerindo que a seca por si mesma não é razão suficiente para a maioria da mudança de residência. Outra razão para se mudar para novas áreas de plantio é "o ser chamado" pelos parentes. Seis dos $68(9 \%)$ casos de migração eram atribuídos aos jovens rapazes indo ajudar os membros da família extensa no cultivo nas áreas de fronteira.

A alteração ou colapso nas redes de apoio social nos vilarejos de origem também pode disparar a migração. Nas 25 histórias de migração coletadas a nordeste de Lusaca, conversei sobre parentesco e relações sociais nos vilarejos originários. Nove pessoas mencionaram a morte de alguém em quem se apoiavam para assistir às suas necessidades. Um homem dependia de seu pai para auxilio no vilarejo, inclusive terra, mas seu pai morreu em 1968. Por volta de 1970 , o filho se estabeleceu com um irmão mais velho no Oeste de Lusaca porque os parentes matrilineares tomaram controle da terra do falecido e deixaram o filho sem nada. Em outro caso, dois irmãos assistiam regularmente um ao outro quando tinham problemas no vilarejo, mas o mais velho morreu e, três anos depois, o irmão mais novo se mudou para a fronteira, onde alguns dos seus filhos tinham se estabelecido. Isso é comum: quando a rede de apoio nos próprios vilarejos se irrompe, as pessoas reassentar-se-ão em uma área onde outras opções de segurança social estão disponíveis.

Outro importante elemento para entender o processo migratório da Província Sul é o processo temporal das mudanças domiciliares. Meus dados da área de Monze vêm dos anciãos e vizinhos e não dos específicos indivíduos que migraram. Consequentemente, tenho esquemas temporais gerais mais do que datas específicas de partidas dos vilarejos para 105 indivíduos (ver Tabela 4). Metade dessas pessoas (53 casos) deixou seus próprios vilarejos para a região da linha de ferro na Província Sul depois das eleições multipartidárias em 1991. Esse período coincide com as secas do início e meados dos anos 1990, tanto quanto a reestruturação econômica que seguiu o novo governo. Dessas 53 migrações desde 1991, aproximadamente 20 pessoas escolheram mudar-se durante e depois da seca de 1995. O início 
dos anos 1980 também era o período da severa seca e do caos econômico. Aproximadamente 27\% (28 casos) das migrações ocorreram durante esse período. Essa informação certamente apoia noções do papel que os fatores ambientais e econômicos desempenharam nas decisões migratórias. Claro que quando a escassez dos recursos aumenta, tanto no caso da seca como no conflito e na tensão social, também aumenta a escala de pessoas em busca da satisfação de suas necessidades. Nesse caso, então, os componentes socioeconômicos na tomada de decisão tornam-se inextricavelmente vinculados.

\section{TABELA 3 - RAZÕES DE MIGRAÇÃO PARA ÁREAS DE CULTIVO NA FRONTEIRA DA AMOSTRA MONZE}

\begin{tabular}{lcc}
\hline & $\mathbf{N}$ & $\mathbf{\%}$ \\
\hline Problemas de acesso a recursos e conflito sobre & 51 & 76 \\
recursos, especialmente terra & & \\
$\begin{array}{l}\text { A seca } \\
\text { Parentes na fronteira buscam ajuda de parentes mais }\end{array}$ & 8 & 12 \\
jovens nos vilarejos de origem & 6 & 9 \\
Casos judiciais nos vilarejos de origem & 2 & 3 \\
Total & 67 & 100 \\
\hline
\end{tabular}

FONTE: Chefes e anciãos do vilarejo

TABELA 4 - MIGRAÇÕES POR ANO (ERA) PARA MIGRANTES DE MONZE E ÁREAS DE FRONTEIRA

\begin{tabular}{lcc}
\hline & $\mathbf{N}$ & $\mathbf{\%}$ \\
\hline 1991 a 1996 & 53 & 50 \\
Década de 1980 às eleições multipartidárias (1991) & 28 & 27 \\
Independência ao final dos anos 1970 & 14 & 13 \\
Antes da Independência & 10 & 10 \\
Total & 105 & 100 \\
\hline
\end{tabular}

Uma observação dos casos de migração eu recordo que ocorreu antes da austeridade econômica e climática dos anos de 1980 e de 1990. Treze por cento ( 14 casos) de migrações aconteceram entre a independência e o final dos anos de 1970 e outros dez por cento aconteceram antes da independência. A Província Sul tinha sido uma das áreas mais densamente 
populosas da Zâmbia, especificamente devido às condições ideais para a agricultura que predominaram no passado. Três quartos das migrações das quais eu tinha dados ocorreram desde os anos 1980; este número deve refletir, em parte, o aumento da população na região. Isto se justifica pelos dados de migração que temos da região antes do início da independência, quando a terra era mais fértil e abundante, e sugerem que as motivações para migração incluem mais fatores complexos do que as óbvias pressões econômicas e ecológicas.

Ajustando entre si a variedade de motivações para migrar, vemos a complexidade e a sutileza de tais decisões. As estruturas sociais e o acesso aos recursos são entrelaçados para possibilitar ou impedir as estratégias locais de sobrevivência. Essas estruturas podem influenciar a decisão individual de migração tanto quanto os fatores macroeconômicos, como a seca e o distúrbio econômico nacional. Para melhor entender o processo migratório, precisamos permitir que motivações menos explícitas entrem em nossos modelos de decisões migratórias, incluindo fatores social e culturalmente construídos, como as relações de parentesco local e de poder.

\section{Conclusão}

$\mathrm{O}$ artigo enfatizou o complexo ambiente socioeconômico em que os indivíduos e seus parentes tomam decisões migratórias. Identificar os atores individuais nos processos de tomada de decisão é difícil por diferentes razões, inclusive estereótipos de família homogênea, cooperativa e altruísta e unidades de agregados. Os dados apresentados nesse artigo sugerem que enquanto as pessoas vivem e trabalham dentro de um modelo de família e parentesco, diferentes objetivos e desejos conduzem os indivíduos a encontrar suas próprias soluções para conflitos domésticos e lutar por acesso a recursos. Em muitos casos, a migração pode aliviar conflitos em casa.

A distinção entre a influência da estrutura e o conflito social nas decisões migratórias versus a visão sobre os privilégios obtidos por incentivos econômicos e os supostos grupos domésticos altruístas torna-se, particularmente, importante quando tentamos entender as ligações dos 
migrantes com seus próprios parentes. Algumas vezes os migrantes não enviam remessas; outras vezes eles não buscam manter contato com seus parentes no vilarejo; e ainda, em outros casos, eles escolhem não retornar para suas próprias comunidades depois do que se tornou uma migração temporária. Nesses casos, deveríamos olhar para a natureza das estruturas sociais e relações de poder nas próprias comunidades como componentes da alta complexidade do processo migratório.

Enquanto essa discussão esquematizou um exemplo regional de migração interna na África, as questões levantadas podem ser associadas a uma discussão maior sobre o processo migratório. No México rural, as dinâmicas de poder no nível dos vilarejos influenciam a migração de pelo menos duas comunidades na península do Yucatán (HAENN, 1999) e, na Nigéria, as ameaças de bruxaria e estruturas de parentesco inspiram a mudança domiciliar externa das fronteiras dos vilarejos (STONE, 1997). Esses estudos demonstram a importância das estruturas sociais fundamentais que influenciam o acesso aos recursos, em particular o ambiente socioeconômico em que as pessoas tomam suas decisões. Adicionar o componente da contenda social para nossos modelos de migração cria uma visão mais acurada da vida cotidiana que tentamos entender. Quando reduzimos causas e efeitos a elementos que se encaixam de forma adequada em nossos modelos estatísticos, em geral eliminamos tanto a realidade como as características profundamente ingênuas das pessoas que estudamos. Para documentar suas vidas mais honestamente, devemos desenvolver uma visão holística das motivações por tomada de decisão que incluem ambos os incentivos, econômicos e sociais, no processo de migração.

\section{Referências}

ANTEL, J. J. Returns to migration: literature review and critique. Santa Monica, California: National Institute of Child Health and Human Development, 1980.

ASHBAUGH, L. The Great East Road: gender, generation, and urban to rural migration in the Eastern Province of Zambia. PhD Dissertation - Northwestern University, Department of Anthropology, Evanston, Illinois, 1996. 
BECKER, G. S. A treatise on the family. Cambridge, Massachussets: Harvard University Press, 1981.

BERTRAM, G. The MIRAB Model twelve years on. The Contemporary Pacific, v. 11, p. 105-123, 1999.

BOND, V.; CLIGGETT, L.; SCHUMACKER, L. STDs and intra-rural migration in Zambia: interpreting life histories of Tonga migrants in relation to the transmission of STDs and HIV. Bloomington, Indianapolis: Population Institute for Research and Training, 1997.

BOSERUP, E. The conditions of agricultural growth. Chicago: Aldine, 1965.

CENTRAL STATISTICS OFFICE. ZAMBIA(CSO). Internal migration and urbanization, aspects of 1990 census of population, housing, and agriculture. Lusaka, Zambia: Central Statistics Office, 1995.

CHIPINGU, S. African leadership under indirect rule in Colonial Zambia. In: (Org.). Guardians in their times: experiences of Zambians under Colonial Rule. London: Macmilian, 1992. p. 50-73

CLIGGETT, L. My mother's keeper changing family support systems for the elderly in the Gwembe Valley, Zambia. Tese - Indiana University Department of Anthropology, Bloomington, Indiana, 1997.

COLSON, E. Marriage and family among the Plateau Tonga. Manchester, Reino Unido: Manchester University Press, 1958.

. Social organization of the Gwembe Tonga. Manchester, Reino Unido: Manchester University Press, 1960.

. Social consequences of resettlement. Manchester, Reino Unido: Manchester University Press, 1971.

. The resilience of matrineality: Gwembe and Plateau Tonga adaptations. In: CORDELL, L.; BECKERMAN, S. (Org.). The versatility of kinship. New York, Estados Unidos da América: Academic Press, 1980.

. The consciousness of disputes. In: CAPLAN, P. (Org.). Understanding disputes: the politics of argument. Oxford: Berg, 1995a, p. 65-82.

. War and domestic violence. Cultural Survival, v. 19, n. 1, p. 35-38, 1995 b.

. The Bantu Botatwe: changing political definitions in Southern Zambia. In: PARKIN, D.; CAPLAN, L.; FISHER, H. (Orgs.). The politics of cultural performance. Oxford: Berghahn, 1996. p. 61-80.

. The sins of the fathers. Unpublished manuscript, 1998. 
; GLUCKMAN, M. Seven tribes of British Central Africa. London: Oxford University Press, 1951.

; SCUDDER, T. New economic relationship between the Gwembe Valley and the line of rail. In: PARKIN, D. (Org.). Town and country in Central and Eastern Africa: studies presented and discussed at the $12^{\text {th }}$ International African Seminar. Lusaka, September, 1972. London: Oxford University Press, 1975. p. 190-210.

. Old age in Gwembe District, Zambia. In: AMOSS, P. T.; HARRELL, S. (Orgs.). Other ways of growing old: anthropological perspectives. Stanford, California: Stanford University Press, 1981.

DaVANZO, J. Microeconomic approaches to studying migration decisions. Santa Monica, California: National Institute of Child Health and Human Development, 1980.

DeJONG, G. F.; GARDNER, R. W. (Orgs.) Migration decision making: multidisciplinary approaches to microlevel studies in developed and developing countries. New York: Pergamon Press, 1981.

DWYER, D.; BRUCE, J. (Orgs.). A home divided: women and income in the Third World. Stanford, California, Stanford University Press, 1988.

EPSTEIN, A. L. Politics in an Urban African community. Manchester, Reino Unido: Manchester University Press, 1958.

GREENHALGH, S. Intergeneration contracts. In: DWYER, D.; BRUCE, J. (Org.) A home divided: women and income in the Third World. Stanford, California: Stanford University Press, 1988. p. 39-70.

GUYER, J. Household and community in African Studies. African Studies Review, n. 24 , v. 2/3, p. 87-137, 1981.

HAENN, N. Community formation in frontier Mexico: accepting and rejecting new migrants. Human Organization, v. 58, p. 36-43, 1999.

HAYES. G. Migration, metascience and development policy in Island Polynesia. The Contemporary Pacific, v. 3, p. 1-58, 1991.

JONES, R. C. Ambivalent journey: U.S. migration and economic mobility in North-Central Mexico. Tucson: University of Arizona Press, 1995.

LUCAS, R.; STARK, O. Motivations to remit. Evidence from Botswana. Journal of Political Economy, v. 93, p. 901-918, 1985.

MASSEY, D. S. The social and economic origins of immigration. Annals of the American Academy of Political and Social Science, v. 510, p. 60-72, 1990. 
. Contemporary theories of international migration. Population and Development Review, v. 19, p. 431-466, 1993.

; ALARCON, R.; DURAND, J.; GONZALEZ, H. Return to Aztlán: The social process of international migration from Western Mexico. Berkeley: University of California Press, 1987.

; ARANGO, J.; GRAEME, H.; KOUAOUCI, A.; PELlEGRINO, A.; TAYLOR, J. E. (Orgs.). Worlds in motion: understanding international migration at century's end. Oxford: Oxford University Press, no prelo, n.d.

TODARO, M. P. Economic development. E.U.A., New York: Longman, 1994.

MINISTRY OF AGRICULTURE, FOOD AND FISHERIES, ZAMBIA (MAFF). Sustainable options for increased food production in Zambia. Lusaka, Zambia: Ministry of Agriculture, Food and Fisheries, 1995.

MITCHELL, J. C. The Kalela dance: aspects of social relationships among urban Africans in Northern Rhodesia. Manchester, Reino Unido: Rhodes-Livingstone Institute, 1956.

MOORE, H.; VAUGHAN, M. Cutting down trees: gender, nutrition, and agricultural change in the Northern Province of Zambia (1890-1990). Porstmouth, N. H.: Heinemann, 1994.

NETTING, R. Smallholders, householders: farm families and the ecology of intensive, sustainable agriculture. Stanford, California: Stanford University Press, 1993.

; WILK, R.; ARNOULD, E. Households: comparative and historical studies of the domestic group. Berkeley: University of California Press, 1984.

OHADIKE, P. Demographic perspectives in Zambia. Lusaka, Zambia: Institute of African Studies, University of Zambia, 1981.

SAVORY, T. Moorings farm rainfall records from 1914 to present. Unpublished data, 1996.

SCUDDER, T.; HABARAD, J. Local responses to involuntary relocation and development in the Zambian portion of the Middle Zambezi Valley. In: MOLLET, J. A. (Org.). Migrants in agricultural development: a study of intra-rural migration. London: Macmillian, 1991. p. 178-205.

SELETI, Y. N. Entrepreneurship in Colonial Zambia. In: CHIPUNGU, S. (Org.). Guardians in their times: experiences of Zambians under Colonial Rule. London: Macmilian, 1992. p. 147-179.

SINGER, A.; MASSEY, D. S. The social process of undocumented border crossing among Mexican migrants. International Migration Review, v. 32, p. 561-593, 1998. 
STARK, O. The migration of labor. Cambridge, Mass.: Basil Blackwell, 1991.

STONE, G. D. Predatory sedentism: intimidation and intensification in the Nigerian Savanna. Human Ecology, v. 25, p. 223-242, 1997.

STUCKI, B. Economic development. New York: Longman, 1995.

TOWNSEND, N. Men, migration, and households in Botswana: an exploration of connections over time and space. Journal of Southern African Studies, v. 23, p. 405-420, 1997.

UDVARDY, M.; CATELL, M. Gender, aging and power in Sub-Saharan Africa: challenges and puzzles. Journal of Cross Cultural Gerontology, v. 7, p. 275-288, 1992. VAIL, L. The political economy of East-Central Africa. In: BIRMIGHAM, D.; MARTIN, P. M. (Orgs.). History of Central Africa. London: Longman, 1983. p. 200-250.

WILK, R. (Org.). The household economy. Boulder, Colo.: Westview Press, 1989. .Household ecology: economic change and domestic life among the Kekchi Maya in Belize. Tucson: University of Arizona Press, 1991.

Recebido em janeiro de 2012. Aprovado em abril de 2012. 